\title{
La literatura como realidad trascendida: narrativas de la Violencia en Detrás del rostro*1
}

Carolina Marrugo Orozco ${ }^{2}$

Investigadora Independiente

ORCID: 0000-0001-5165-9655

Recibido: 10 de diciembre de 2019

Aceptado: 02 de marzo de 2020

\section{RESUMEN}

A mediados del siglo XX en Colombia, se expusieron nuevas formas narrativas, algunas de ellas con tinte de denuncia, acompañado por una implícita agencia política de sus autores. La novela Detrás del rostro (1963) del escritor colombiano Manuel Zapata Olivella se inscribe en esta tendencia. Esta será nuestra fuente primaria para analizar desde un marco socio-histórico el valor de la obra, desde el enfoque metodológico de la sociología de la literatura. En este sentido, se realizará un análisis y contraste del momento histórico y social en el cual se inscribió esta producción, la Violencia (con mayúscula), por medio del registro de la prensa nacional de mitad de siglo, que permitirá contrastar el contexto de Colombia con las situaciones representadas en el libro.

Palabras clave: Narrativas, Violencia, siglo XX, agencia, Manuel Zapata Olivella.

\begin{abstract}
In the mid-twentieth century in Colombia, new narrative forms were exposed, some of them with complaint dye, accompanied by an implicit political agency of their authors. The novel Behind the Face (1963) by Colombian writer Manuel Zapata Olivella is part of this trend. This will be our primary source to analyze the value of the work from a socio-historical framework, from the methodological approach of the sociology of literature. In this sense, there will be an analysis and contrast of the historical and social moment in which this production was registered, Violence (with capital letter), through the registration of the national press of half a century, which will allow to confront the context of Colombia with the situations represented in the book.
\end{abstract}

Keywords: Narratives, Violence, twentieth century, agency, Manuel Zapata Olivella.

\footnotetext{
* Literature as a transcended reality: Narratives of Violence in Detrás del rostro

${ }^{1}$ Este artículo se deriva de mi trabajo de investigación sobre Campo intelectual y artístico en Latinoamérica y el Caribe a mediados del siglo XX, trabajo que hasta el momento se había inscrito en la producción pictórica de mujeres pero que amplió su espectro de análisis hacia una producción de discursos y narrativas más extensos teniendo en cuenta la participación de los hombres, comprendido desde las dimensiones de género que intentan destacarlo en la realidad social como el conjunto de relaciones dinámicas en un contexto y tiempo determinado.

${ }^{2}$ Magíster en Historia. Universidad Andina Simón Bolívar-Quito, Ecuador. Investigadora independiente. Coordinadora y docente del área de Sociales. Catedrática de investigación y Análisis literario en la educación básica secundaria (Bogotá-Colombia). Correo: histpanico@gmail.com
} 


\title{
INTRODUCCIÓN
}

\begin{abstract}
"Si en la búsqueda de los temas de la violencia el escritor dejara de observar por un instante los crímenes y los incendios, para iniciar la novela por el final y no por el comienzo, encontrara a más de un protagonista en vida y sin nombre"
\end{abstract}

Manuel Zapata Olivella. Prólogo. Detrás del rostro

A pesar de que en Colombia se evidencia un notable esfuerzo, en términos historiográficos, por establecer diálogos interdisciplinares, en especial con la literatura (Arboleda, 2011: 360) la agencia de personajes como el escritor loriqueño Manuel Zapata Olivella (1920-2004) continúa como asignatura pendiente. ${ }^{4}$ Tanto en el canon histórico como literario, permanecen paradigmas encarnados en las figuras de artistas e intelectuales como Gabriel García Márquez, Alejo Carpentier, Jorge Luis Borges, Mario Vargas Llosa, entre otros, en los cuales queda depositado gran parte del reconocimiento social, por demás válido, sobre la producción literaria y humanística en Latinoamérica. Sin desmeritar esta realidad que intenta subrayar el trabajo de estos escritores, el sentido del reconocimiento exige colocar a disposición otras obras y artistas en los cuales es posible palpar la esencia misma de nuestro continente: múltiples voces guaraníes, negras, mapuches y otros actores sociales como mujeres, niños, campesinos, etc., que en el universo literario e histórico requieren mayor representación.

Así las cosas, Manuel Zapata Olivella se convierte en una excusa para interpelar esta realidad histórico-literaria canónica y convencional que nos sumerge en el círculo de unos pocos. Siendo válido el proceso de creación como resultado de múltiples experiencias, la coyuntura del giro cultural nos permite exponer otras producciones, voces y ejercicios de creación en clave socio-histórica y que, además, proponen a la realidad social como insumo de la escritura. La novela Detrás del rostro (1963) nos invita a pensar este ejercicio, a la luz del presente, como una forma de producción artística que plantea re-lecturas del contexto histórico de la primera Violencia en Colombia. ${ }^{5}$ Esto es, la obra que nos permite reconocer no sólo la participación e inclusión del intelectual negro en el campo artístico de mediados del siglo XX, sino el conjunto de prácticas de sentido que aplicó en su ejercicio de creación literaria para rastrear los límites y posibilidades presentes en su discurso.

Autores como Manuel Zapata Olivella aún siguen constituyéndose en una especie de "rareza" del campo literario e intelectual colombiano de mediados del siglo XX, por su constante y multifacética

\footnotetext{
${ }^{4}$ Hago esta afirmación como producto de mi experiencia desde la investigación en el campo cultural de América Latina y el Caribe en la segunda mitad del siglo XX, al hablar con colegas latinoamericanos, en especial de Suramérica donde es prácticamente desconocida la obra de este autor. ${ }^{5}$ Una historia de la literatura puede ser pensada desde las condiciones de posibilidad de etnia, clase, género y raza, como ya se ha planteado desde la disciplina histórica. Desde el plano metodológico esto podría abordarse desde la visión de la historiadora Suzy Bermúdez, que nos propone cruzar estas variables para tener una comprensión más amplia de realidades históricas más específicas. Siendo Manuel Zapata Olivella un intelectual negro en el campo literario de mitad de siglo XX en Colombia y Latinoamérica, cabe preguntarse por el sentido de su presencia en la cultura como un reflejo del conjunto de posibilidades de raza, género y etnia propiciado en el mundo de las letras.
} 
presencia dentro de las letras y la cultura (Ver figura 1). Su trabajo incluye la participación en el cine, la crítica literaria, la antropología cultural y la dirección editorial, entre otros, que le valió un amplio reconocimiento en el campo artístico. Su agencia en el espacio de la Radiodifusora Nacional de Colombia le permitió integrar de forma magistral conocimientos amplios sobre medicina, botánica, saberes ancestrales, folclor, literatura, lenguaje, costumbres y tradiciones. Por otro lado, el espacio de la revista Letras nacionales le permitió impulsar la producción narrativa de Colombia en clave crítica, pues uno de sus mayores intereses fue la reflexión sobre la identidad nacional como un factor determinante para comprender nuestra diversidad. En este trabajo, aspectos como la cultura, la ciencia y la historia se constituyeron en la materia prima para indagar sobre las relaciones entre la región y la nación. Cabe decir que en el programa "Identidad Nacional" dirigido por Zapata en la Radiodifusora Nacional de Colombia se dedicó a dar cuenta no sólo de su bagaje bibliográfico, sino del conjunto de recursos desde la oralidad como insumos de investigación. ${ }^{6}$

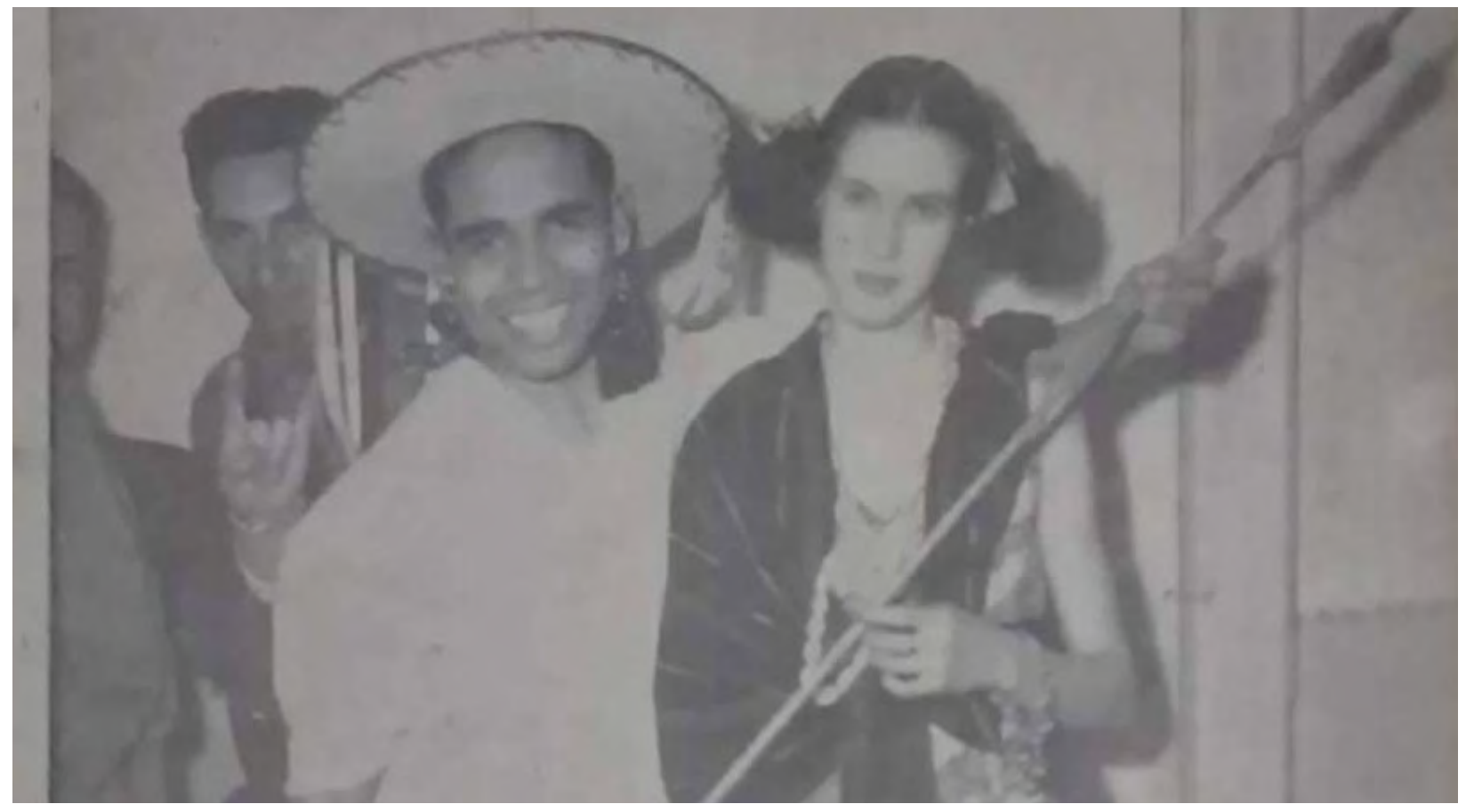

Figura 1. Manuel Zapata Olivella en México. Fuente: Revista Cromos. Manuel Zapata Olivella "Un colombiano en el cine azteca "Bogotá, 1949. Biblioteca Nacional de Colombia.

La presencia y agencia de Manuel Zapata Olivella en el campo artístico e intelectual de mediados del siglo XX posibilita reconocer también un contexto internacional que coadyuvó a promover espacios de intercambio cultural entre distintos países como se reconoce a partir de su gestión editorial (Ver figura 2). Esta realidad permite identificar el diálogo y la posibilidad de convergencias y trayectorias culturales presentes en el ámbito latinoamericano. A lo largo del siglo XX, las revistas

\footnotetext{
${ }^{6}$ En este sentido, quiero destacar la participación de Manuel Zapata Olivella en la Radiodifusora Nacional de Colombia desde donde emitió y dirigió programas y espacios culturales como radionovelas, conferencias y comentarios sobre cuentos folclóricos. Ver Señal Memoria. Manuel Zapata Olivella. Un caminante de la literatura y la historia.
} 
culturales, entre ellas Cromos, Civilización, Letras Nacionales, Mito, Plástica, Espiral y Prisma ocuparon el mundo de las letras y de la cultura desde distintas perspectivas. En la revista Mito, dirigida por Marta Traba, por ejemplo, fue posible reconocer un interés por la literatura francesa y alemana, mientras que Plástica dirigida por Judit Márquez y Prisma también bajo el liderazgo de Traba se dedicaron exclusivamente a generar espacios de crítica de la pictórica nacional. Esta amplia producción cultural dio cuenta no sólo de grados de especialización de diversos espacios del campo artístico, sino de la resonancia crítica que subyacía sobre la figura variada y multifacética de autores o pintores como agentes culturales de su época (Bourdieu, 1980:32). La experiencia de Manuel Zapata Olivella, así como la de escritores y artistas contemporáneos a él como Héctor Rojas Herazo, Nereo López, Gabriel García Márquez, Cecilia Porras, Alejandro Obregón, Enrique Grau, Fanny Buitrago, Dora Castellanos, entre otros, estuvo comprometida con una mirada crítica y una expresión de la cultura regional en estos espacios de producción. Su interés resaltó en gran medida el relato, la pictórica y los reportajes gráficos como estrategia narrativa. Ya en este espacio se percibe un interés particular de esta generación por exponer el desencuentro de los sujetos con el contexto de Violencia y modernización presente en el país (Buhsnell, 1994: 275).

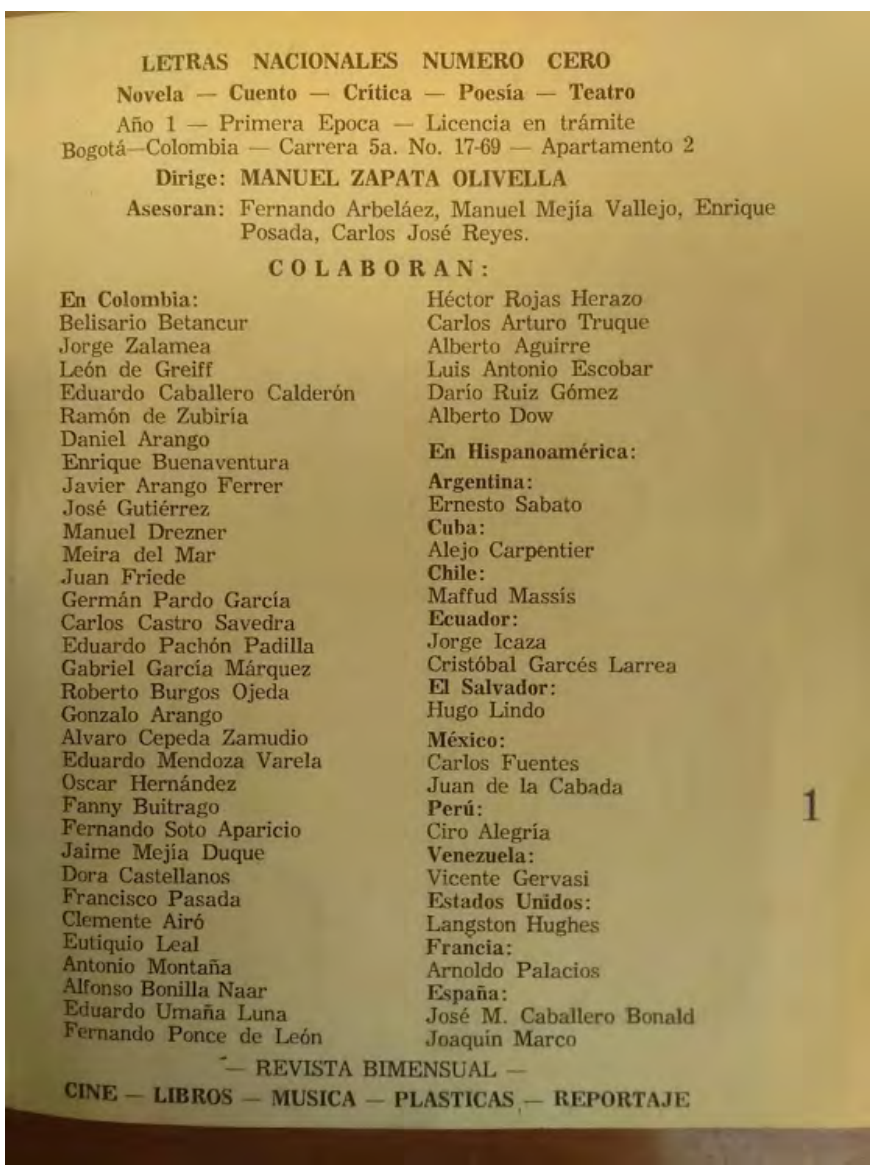

Figura 2. Índice del Número 0 de la revista Letras Nacionales. En este se puede evidenciar el conjunto de autores $\mathrm{y}$ autoras nacionales y extranjeros colaboradores.

Fuente: Revista Letras Nacionales. Biblioteca Nacional de Colombia. Enero-Febrero de 1965 
Lo anterior posibilita reconocer la presencia de una novela como Detrás del rostro (1963) en la cual los márgenes de la ficción y la realidad quedan confusos. La puesta en escena de esta práctica escritural y la realidad social que la constituye evidencian nuevas pautas del lenguaje que incluye el modelo de experiencia de sus personajes: son sujetos que dejan conocer sus historias de vida, temores e incertidumbres. Por otro lado, el autor nos deja conocer un contexto que expone el desarrollo de una estructura social y política atravesada por experiencias de violencia íntima, psicológica y social. Se entretejen en ello las relaciones del sujeto con los estamentos de autoridad, con el tiempo, con su misma existencia y consciencia. Esta es una escritura que reconoce los ritmos de la vida moderna retratados a partir de los contrastes de la cotidianidad. Y con ello, concede una identidad a nuevos actores sociales como mujeres, niños y campesinos que dejan entrever su estructura mental dentro de la historia y en los cuales se marcan crudas realidades atravesadas por su condición social. Es, en este sentido, que la presencia de Manuel Zapata Olivella como negro intelectual evidencia en sí mismo una agencia como autor que se preocupa por reconocer en su contemporaneidad un insumo prolífico y crítico para la reflexión histórica (Bloch, 2001: 41).

El acompañamiento que hemos propuesto para contrastar esta lectura a la que invita Manuel Zapata Olivella en Detrás del rostro se hace desde la prensa. Dos formas de puesta en escena o de interpretación de una realidad en tanto ficción por ser construida, permite instalar dos formas de discursos que ostentan la presencia de actores sociales y de un contexto en los cuales se facilita reconocer su inserción. El período de exposición de estos discursos, aunque distantes en su cronología, permiten reconocer la continuidad de ciertos imaginarios que recayeron sobre los sectores populares, casi siempre en vía negativa. La "dosis de realidad" que exponen ambos tipos de producción con el rango de una década sólo nos remite a identificar la permanencia de discursos sobre determinados sujetos, esto es, formas de representación escritural tanto en el mundo social, -prensa-, como en el universo literario, -novela.

Este interés surge de reconocer en el siglo XX aquellas profundas huellas políticas y económicas que hundían sus raíces en las postrimerías del siglo anterior, desencadenando la brutal confrontación de los Mil Días, hasta encontrar su clímax con la separación de la provincia de Panamá y hacer tránsito hacia la tortuosa experiencia de la gran depresión de 1930. Así pues, entrando a los años treinta, el país -hasta entonces rural- fijó sus derroteros en nuevas perspectivas de desarrollo, cuando los liberales, inspirados en los ideales de la modernización, asumieron el poder y reorientaron los propósitos nacionales con tendencia a superar esas crisis sociopolíticas y, por ende, propiciar el desarrollo de las artes y la educación a nivel de masas ${ }^{7}$ (Casas, 2006: 67). Es en este contexto donde surge un interés que en su conjunto se articula con una tendencia internacional por comprender y expresar realidades sociales de sectores populares a partir de los distintos espacios como la pictórica y la literatura, que se conjugaron en la resonancia de tres elementos: discursos, prácticas y representaciones.

\footnotetext{
${ }^{7}$ Posterior a la Revolución mexicana y a la crisis de la Primera Guerra Mundial, América Latina experimentó uno de los periodos de mayor agitación social, política y cultural, que involucró algunos rezagos regionales decimonónicos.
} 
A la luz del presente, esta historia cultural de la literatura se asume como una lectura de los discursos insertos al interior de la obra y las prácticas de sentido en que residen las representaciones expuestas dentro de la narrativa. Con este insumo, se propone instalar una posibilidad ya abierta de comprender la literatura como una fuente histórica, desde la cual es posible remitirnos a dimensiones del contexto de producción y elaboración de dichos discursos, así como la medida en que estos se articulan o desvinculan de la realidad social y política en la cual se inscriben. De acuerdo a lo anterior, este trabajo presenta dos ítems: el primero se titula "Literatura y contexto: el mundo cultural y la agencia de Manuel Zapata Olivella en el siglo XX", en el cual se reflexiona sobre el lugar de la literatura en dicho contexto en Colombia atendiendo a la presencia específica de Manuel Zapata Olivella. Y en el segundo apartado, "Detrás del rostro: re-lecturas de la realidad colombiana a partir de la literatura", se hará una descripción de los elementos de la obra literaria en relación con la dimensión personal, social y política que representa.

\section{Literatura y contexto: el mundo cultural y la agencia de Manuel Zapata Olivella en el siglo XX}

E1 23 de Julio de 1950, casi una década antes de que se publicara la novela Detrás del rostro (1963) del escritor loriqueño Manuel Zapata Olivella, la prensa nacional publicaba en el diario El colombiano el siguiente reportaje:

[...] Estas gentes enfermas, que tienen que sobrevivir representan en los puestos, en las casas de beneficencia, las cargas para sus familias, los gremios parásitos como los mendigos y las meretrices y solamente en una escala reducidísima cierto número de trabajadores independientes sin capital. (Editorial, El colombiano, 1950)

Esta noticia expone la forma en que la prensa conservadora representó la situación de algunos sectores populares de la época. Para mediados del siglo XX, los colombianos sufrían los embates de la pobreza y la marginalidad provocada en gran medida por el contexto social y político derivado de la violencia. Las cárceles, hospitales, asilos y casas de beneficencia se constituyeron en espacios de presencia de sectores menos favorecidos. Por supuesto la presencia de este y otros discursos sobre el problema de asistencia social respondían a intereses marcadamente políticos, pues en esta época los discursos de la prensa eran esencialmente partidistas (Banrep, 2019:1).

Periódicos como El Colombiano y El Espectador, de filiaciones contrarias, solían convertirse en tribunas sobre asuntos de orden nacional como las políticas de asistencia social, la participación política de las mujeres y el eterno fantasma de la amenaza comunista. De forma paralela, fue también el período en que las revistas culturales expusieron con intensidad la autoría de los intelectuales extranjeros y colombianos quienes, a través de las letras y la pictórica, exponían sus opiniones sobre diversos temas, algunos de tinte político asociados con crítica hacia el gobierno ${ }^{8}$

\footnotetext{
${ }^{8}$ Este aspecto se relacionó más con una preocupación de los artistas por el poco apoyo económico que recibían de las instituciones del gobierno.
} 
De esta forma, la escritura fue uno de los vehículos para exponer esta realidad en la prensa prolongándose ya con menos fuero hasta el Frente Nacional. Bajo la semántica de lo "civilizado," lo "moderno," y" el progreso", se construyó un nuevo paradigma del devenir humano a la par de la experiencia de la violencia. Así, frente a la expectativa de modernización, como lo indicó el historiador David Bushnell (1994), este escenario se concretó en una realidad paradójica de pandemónium político versus el crecimiento económico (281).

En este contexto hizo su presencia un nuevo orden cultural: nuevas formas estéticas asociadas al movimiento vanguardista renovaron el campo intelectual y artístico de Colombia a mediados del siglo XX (Medina, 2019: 1). Estas circunstancias propiciaron un acercamiento al mundo social y político a partir de las experiencias relacionadas con la modernidad, el orden geopolítico y las tensiones globales. Es entonces cuando la producción narrativa colombiana adquiere nuevos matices que operan en los lindes de la creación, la ficción y la crítica. En este sentido, desde nuestra perspectiva podemos decir que bajo esta realidad, las diversas formas del arte como pintura, escritura e inclusive prensa empiezan a exponer la crudeza de la realidad nacional e internacional y se convierten en "espejos" de aquella realidad llena de tensiones. Junto a ello, el contexto se alimentaba de nuevas nociones de nacionalismo y búsquedas de una identidad latinoamericana, en ese momento cuestionado, pero que no dejó de pensarse desde las raíces hispánicas. No en vano, logran convivir realismo y abstraccionismo como tendencias del arte y como una nueva forma de comprender al sujeto en su contexto inmediato, así como su nueva relación con el orden social: pintura y narrativa dedicaron espacios amplios a la crítica social. En este sentido la literatura toma su curso. En el plano narrativo, la escritura ya venía experimentando una nueva dimensión reflexiva en clave sociológica frente al tema de la violencia en Colombia, con las obras La vorágine (1924) de José Eustasio Rivera (Ordóñez, 1999:1) y La marquesa de Yolombó (1928) de Tomás Carrasquilla (Naranjo, 2016:1). Estas producciones proyectaron desde el plano literario, una nueva relación del hombre con su contexto natural, social y político marcado por problemáticas de clase, raza y género: nuevas relaciones marcadas por la presencia de nuevos lenguajes incorporados a partir de los modismos y de la fusión de la relación hombre-naturaleza (Restrepo, 1989: 65).

De aquí en adelante, la literatura colombiana experimentará nuevos intereses sintonizados con la realidad latinoamericana marcada por temáticas como las luchas sociales, la protesta antiimperialista y la exposición de conflictos presentes en las regiones. En este sentido, se anticipó como espacio de crítica de problemas sociológicos que azotaban al país, utilizando la creación literaria como práctica. De esta manera, se enmarcaron auténticas reflexiones como la auto-identificación del hombre latinoamericano como agente de su propia historia.

El contexto de producción de este tipo de literatura tuvo su base en el período histórico denominado la República Liberal (1930-1946), que coincidió con un gran apoyo e interés del gobierno hacia los artistas. Con El Bogotazo e inicio de la llamada Primera Violencia esta tendencia aumentó y 
fue objeto de representación no sólo en la literatura sino en la pictórica. ${ }^{9}$ Cuando aún la historia se hacía tímida con el análisis de temas como la violencia, surgen intentos significativos desde la agencia literaria para evidenciarlos. El despegue de esta tendencia estuvo acompañado de historias vinculadas con la experiencia de la modernidad: tanto para hombres como para mujeres cambió la perspectiva del mundo.

Para los años cincuenta, estas tendencias encontraron un lugar en el conjunto de nuevas relaciones de los actores sociales (hombres, mujeres, niños, campesinos desplazados, etc.) con relación al tiempo, al espacio y a las relaciones interpersonales. De esta manera se presentan historias de migración interna, de explotación, el papel de la clase trabajadora, los cambios en las ciudades, entre otros. Como ejemplo de esta prolífica producción literaria podemos mencionar algunas obras: $E l$ día del odio (1952) de José Antonio Osorio Lizarazo, El Cristo de espaldas (1952) de Eduardo Caballero Calderón, Entre la libertad y el miedo (1952) de Germán Arciniegas, Viento seco (1953) de Daniel Caicedo, Los elegidos (1953) de Alfonso López Michelsen, El gran Burundún-Burundá (1953) de Jorge Zalamea y La Hojarasca (1955) de Gabriel García Márquez, producciones que abanderaron dichas preocupaciones (Restrepo, 1989: 65). En este corpus literario queda incluida Detrás del rostro (1963) de Manuel Zapata Olivella, quien se aventuró a novelar y teatralizar el período de la violencia con la excusa de la identidad incógnita (Ruiz, 1965:1).

La constancia nominal del autor lo ubica en el clan intelectual Zapata Olivella, encabezado por su padre Antonio y sus hermanos Juan y Delia, en quienes se evidenció una vocación temprana hacia las letras y las artes, promovida en gran medida por el acceso a la educación superior y la posibilidad del intercambio cultural a partir de los viajes (Bourdieu, 2011: 121). En el caso de esta red de intelectuales, la esencia misma de sus raíces quedó expuesta en su realidad étnica atravesada por la historia palpable de dos mundos: el americano y el hispano, pues, al parecer, Edelmira Olivella tenía origen español (Díaz-Granados, 2003:12). Esta preocupación por la identidad cultural y el trasfondo de las raíces étnicas acompañaría de forma permanente a la agencia cultural de los hermanos Zapata Olivella.

En el caso de su ejercicio como escritor, Zapata Olivella expone un ejercicio de hiperconciencia narrativa. El autor presenta en su obra Detrás del rostro (1963) una historia articulada al contexto de la Primera Violencia en Colombia que ubica a sus personajes en la lupa de sus experiencias personales como micro-relatos que no se agotan en la intimidad de la propia historia, sino que se despliegan como espiral para explicar la realidad universal de un ser humano en esencia lleno de incertidumbres (Ortega, 2016: 69). ${ }^{10}$ Esta puesta en escena de experiencias familiares frente al

\footnotetext{
${ }^{9}$ Retomo esta enmarcación cronológica de David Bushnell, quien acota este período entre 1946 y 1957: años previos a El Bogotazo hasta el denominado Frente Nacional. Artistas como Débora Arango empiezan a representar hechos históricos vinculados a realidades sociales y políticas. Esta fue quizá la pintora más constante y destacada en este ámbito.

${ }^{10}$ Retomo este concepto de "Hiperconciencia narrativa" para referirme al ejercicio escritural del autor quien se esfuerza por escenificar el diálogo con su propia tradición. En este sentido, es propio decir que estas resonancias se hacen visibles en trazos de situaciones, espacios o discursos: la situación de las mujeres, el lugar de los espacios de tránsito como la ciudad, la cárcel, el hospital, la apropiación del lenguaje médico, jurídico y moral, y la puesta en escena de quienes personifican las entidades de control: el cura, el médico y el policía.
} 
contexto histórico que habitan en el universo literario remite a una mirada a la realidad histórica como insumo de la creación literaria. Lo interesante de esta práctica radica en las resonancias que estimula a partir de la presencia de los sujetos subalternos o los "sin historia" que se apropian en el relato de sus propios destinos y asumen la condena de su realidad. La misma presencia del médico que emprende la búsqueda de Estanislao nos remite a identificar en él al propio autor de la novela, médico de profesión y aficionado por los archivos (Zapata, 1963:19). Esta lectura también logra interpelar nuestro rol de lectores para emprender una búsqueda y conocimiento de la identidad del niño y propone nuevas pautas de relación con el texto que propone Zapata Olivella. Valdría la pena pensar si en este caso en particular ese pacto se quiebra transitoriamente a partir de la perforación de la escritura que el autor nos plantea.

Un aspecto en el que converge el discurso de la prensa conservadora con relación a la novela es la proyección de relatos de la realidad social y política que se insertan en realidades propias de la modernidad, en especial las que competen a las experiencias de la marginalidad de ciertos sectores sociales, como los niños desamparados y las mujeres (Castro-Gómez, 2009: 44). La puesta en escena de la escritura de Zapata en Detrás del rostro no sólo se comprende desde sus dimensiones multiformes y murmurantes, sino que permite comprender la realidad de estos personajes también como textos sobre los cuales yacen experiencias marcadas por diversos tipos de violencia: social, física, psicológica, etc. (De Certeau, 1996:147).

¿Pero es posible reconocer hasta qué punto ese orden de ideas expuestas en la narrativa de Detrás del rostro (1963) posibilita identificar atisbos de la realidad colombiana de mediados del siglo XX? Si bien la función de la construcción del texto literario obedece hasta cierto punto a operaciones de construcción distinta a las del texto histórico, como bien lo expresa Hayden Whyte (1973), estas operaciones impiden reconocer la función de "creación o invención" que también posee la historia (16). Esta paradoja o desencuentro entre la literatura y la historia como formas de representación de una realidad pretenden ser pensadas a partir de esta reflexión desde la "Literatura como realidad trascendida": como ejercicios de ficción en tanto es un ejercicio de re-construcción y re-interpretación constante de la realidad reconocida como historia.

¿Qué contexto temporal habitó Manuel Zapata Olivella y de qué manera nos lleva a conocer el conjunto de posibilidades de producción de esta historia? La coyuntura temporal de mediados del siglo XX en Colombia es conocida como la era de la Primera Violencia. No hay que olvidar que existió un precedente para comprender este fenómeno en Colombia que fue la dictadura bajo el régimen del General José María Melo en 1854, (Samper, 2014:1). Sin embargo, en términos historiográficos, las disputas bipartidistas se ubican desde la fundación de los partidos políticos tradicionales (liberal y conservador) a mediados del siglo XIX, las cuales sumergieron al territorio colombiano en un escenario de inestabilidad política que derivó en múltiples guerras civiles, incluyendo la Guerra de los Mil Días y como efecto la pérdida de Panamá en 1903 (Múnera, 2005: 225). Otros autores se remiten a ubicar la Primera Violencia junto a la coyuntura de El Bogotazo (Braun, 
1987: 20). Mientras estos datos podrían pensarse como mera información, en la novela Detrás del rostro se posibilitan como huellas de la realidad histórica que suelen retomarse transitoriamente dentro de las historias de los personajes, como una excusa y posibilidad para encarar problemáticas sociales. En algunos partes del texto quedan reflejados: "Aquellos hombres de ruanas oscuras, de sombreros alones, confundidos en filas con extranjeros eran simples campesinos venidos a la ciudad buscando empleo" (Zapata Olivella, 1963: 105)

Ya en el marco de la dictadura de Gustavo Rojas Pinilla (1953-1957) se inició un período de participación de las mujeres en el poder y en 1954 se aprobó por la ANAC (Asamblea Nacional Constituyente) el derecho a elegir y ser elegidas, después de múltiples y encarnizadas polémicas en las que participaron las mujeres. Mientras tanto, en el pensamiento moderno (femenino) los ideales del "deber ser" del "bello sexo" prevalecían bajo la influencia del pensamiento europeo que se filtraba a través del arte y la literatura, especialmente la corriente del existencialismo francés liderados por Simone de Beauvoir con El segundo sexo (1949) y El ser y la nada (1943) de Jean Paul Sartre. Este movimiento, aunado a la llegada de la televisión y de una cultura de masas, provocó cambios sociales que motivaron mayor atención sobre las mujeres y los niños, pero esto no dejaba de ser insuficiente frente a la cruda realidad del país por la violencia, ya que una mayor visibilización no implicaba necesariamente que dicha atención haya sido efectiva, a pesar de que la economía iba en ascenso.

El cúmulo de ideas y experiencias que tuvo la modernidad empezó a enfrentarse a realidades contradictoras como la de las mujeres y la de niños, quienes sufrían desamparo por parte del Estado. Los relatos y narrativas pictóricos que enaltecían el trabajo campesino, a las mujeres y al mundo rural empezaron a formar parte de un engranaje más amplio en el concierto internacional con procesos como la Revolución mexicana (1910) y la Revolución Rusa (1917), que repercutieron en un cuestionamiento de varios escritores y artistas jóvenes por los asuntos que les afectaban y con el propósito de construir un ideario que les permitiera expresar de manera auténtica sus realidades sociales (Casas, 2006:67).

En Colombia esta nueva conciencia artística encontró un espacio donde ya existía una tradición que se basaba en un sistema de representaciones fundamentado en la tradición hispánica junto a una tímida tendencia moderna academicista y que había tenido gran injerencia en el proceso de construcción de la nación. Este espacio de conocimiento encontró su base en resultados de la formación artística adjudicada con apoyo gubernamental, especialmente del Ministerio de Instrucción Pública. De esta manera, se inició un proceso de conciencia artística, extendido hasta nuestros días. Podemos hacer referencia a Zapata Olivella como el intelectual que logró poner en distintos escenarios temáticas vinculadas al auto-reconocimiento mediante la cultura y estos análisis se profundizaron desde postulados teóricos con que el escritor abordaba cada tema, hasta la dimensión empírica propia del cronista quien se nutre de la oralidad como potencia de realidad. La metodología que utilizó en particular el escritor para comunicar algunas inquietudes alrededor 
de la violencia es uno de los aportes más significativos de Detrás del rostro, dentro de la cual podemos destacar una magistral apropiación de múltiples lenguajes técnicos, entre ellos el médico y el jurídico. La exposición de las cartas como recurso narrativo, a nuestro parecer, provoca un intento de quebrar el pacto ficcional en determinados momentos de lectura en el cual la trayectoria del relato concede su espacio para distintas voces en las cuales vamos entretejiendo sus historias.

\title{
II. Detrás del rostro: re-lecturas de la realidad colombiana a partir de la literatura
}

\author{
"Novelar la historia y la realidad" \\ Manuel Zapata Olivella
}

A través de ciento sesenta páginas, en Detrás del rostro, obra ganadora del premio ESSO en 1962, Manuel Zapata Olivella nos presenta un relato indiciario sobre la realidad social e institucional de Colombia en el marco temporal del período conocido en la historiografía como la Primera Violencia $^{11}$ (Ginzburg, 1998: 37). Los indicios se presentan como huellas de la escritura y el sentido de la narración, en la cual se van escalonando múltiples situaciones de los personajes que convergen en el misterio de la identidad del niño. Un aspecto interesante de la puesta en escena de esa estrategia narrativa por parte el autor permite relacionar la articulación de preocupaciones del orden social contemporáneas a él re-evaluando a esa sociedad como un texto que puede ser leído y cuyas historias se constituyen en realidades expuestas en la narración. Esta escritura en clave social se vincula necesariamente con un espacio de producción de sentido en el cual el contexto se constituye en insumo de creación (Hall, 1997: 1).

Según la investigadora mexicana Gloria Prado Garduño, es posible comprender el sentido de la literatura como un espacio que posibilita múltiples realidades, de apertura de espacios y de tiempos intersubjetivos (2019: 1). Detrás del rostro se presenta como un lugar de exposición de la relación del ser humano y la sociedad en sus dimensiones existenciales y sociales que dejan entrever la intensa correspondencia y conflictos del individuo con el mundo moderno, pero además, el debate con su propia identidad: el caso de Estanislao puede constituirse en un referente del devenir humano sellado por las expectativas de la modernidad, pero también con el abandono de las instituciones frente a procesos de re-socialización social. En este camino, la novela deja expreso el funcionamiento de un aparato represivo que se funda en el abuso del poder, las estrategias de supervivencia física y emocional y el dilema ético al que se enfrentan constantemente los personajes. En el siguiente fragmento se evidencia esta realidad:

\footnotetext{
${ }^{11}$ El paradigma indiciario es un modelo epistemológico destinado a las Ciencias Humanas propuesto por el historiador italiano Carlo Ginzburg. Se basa en la interpretación de detalles y signos mínimos, a menudo involuntarios, que resultan reveladores. Desde nuestra consideración, la puesta en escena de una estrategia de escritura que reinventa y actualiza su narrativa interna, realiza un acercamiento a este tipo de metodología.
} 
Él no ignoraba que ciertamente aquellas víctimas del abandono social constituirían sus futuros adversarios en el ajedrez del crimen. Pero ¿había necesidad de empujarlos tempranamente al abismo? ¿No sería mejor tratar de rescatarlos a tiempo? Este hombre inescrupuloso, guardián de la sociedad, les negaba toda posibilidad de salvación. (Zapata, 1963: 110)

Las microhistorias que representan la intimidad de los personajes en la novela conceden un valor de auto-identificación con experiencias propias del mundo social de la época: un espacio donde, por un lado, la emulación de prácticas burguesas como viajar, posicionaba en una esfera de privilegio a individuos como Octavio, pero que, por otro, condenaba moral y simbólicamente la transgresión de los valores familiares representado en las mujeres. En ese orden se entendió la situación de Octavio y Susana: "Él y Susana habían tenido otra historia. Casi eran dos extraños. Francia y Tolima. Al reencontrarse ni se sabían consanguíneos. Un día después de apasionarse mutuamente, supieron de su primazgo por líneas maternas" (Zapata,1963: 93).

La sensibilidad que se plasma en la obra también se desplaza a la experiencia de Ana Peñaranda con Estanislao y del mismo Octavio Guzmán. Ambos, de forma sucedánea, deciden adoptar a un aparente "hijo de la violencia" despojado de toda esperanza por aquellos Bandoleros del Tolima, en aquel espacio hostil degradado por las más bajas miserias y habitado por agentes del terror en un período oscuro de nuestra historia política. Retomando la voz de Octavio en aquella escena posterior al "rescate" de Estanislao, este expresa:

Volví a la pieza donde debía tener encerrado a Estanislao. Introduje la llave en la cerradura y abrí la puerta. Me acerqué al rincón donde permanecía acurrucado. Traté de ganarme su confianza: -¿cómo te encuentras? Se tapó la cara con las manos sin dejar de observarme por entre los dedos. -Vamos a ver a tus parientes antes de que los entierren. (Zapata, 1963: 64)

A propósito de esta referencia geo-espacial dentro de la obra, hay que recordar que este universo ficcional que narra Zapata Olivella coincide con la geografía de la violencia que describió Orlando Fals Borda en el texto sociológico La violencia en Colombia (1958: 287). Y a propósito de esto, dentro de la novela Octavio representa a ese individuo que se desmarca de su territorio para formarse en el extranjero y que a su regreso asume una nueva forma de ver el mundo, a veces alejado de la cruda realidad que le rodea: "Dice el Doctor Piedrahíta a Octavio: Hemos recibido informes de que han visto a extraños merodeando por aquí. Es mejor que nos escuches Octavio. Te imaginas estar todavía en Europa." (Zapata, 1963: 41).

Por otro lado, en el aspecto de la estrategia narrativa del autor, la novela nos presenta un recorrido de múltiples historias que quedan expuestas a partir de los propios relatos de los personajes. Este desplazamiento intencional del relato se convierte en intervenciones narrativas (desde la mirada en retrospectiva de cada uno) que fracturan la linealidad del texto y producen un efecto de oralidad testimonial que perforan la escritura haciendo de estas mediaciones, conversaciones sumergidas 
(Ortega, 2016: 94). En este aspecto, la narración va tejiendo su sentido a partir del micro-relato de los personajes que giran alrededor de la búsqueda de la identidad del niño. Esto es, con relación al tiempo y al espacio se rompe una estructura lineal, causal y racional del relato para desbordar el texto y permitirnos definir a los personajes.

La incertidumbre inicial y constante por la identidad del niño va a ser el eje central de ese desmembramiento cronológico a partir del cual se emprenden ejercicios de memoria por parte de los personajes, desembocados en sus propios relatos testimoniales. En este sentido, el personaje de Ana Peñaranda, mujer que decide acoger a Estanislao, expone en la historia: "Me llamo Ana Peñaranda. Vivo en la Calle veintidós con Carrera Décima. Pero mire yo no sé gran cosa de él. Lo conocí ocasionalmente y le entregué la vigilancia del almacén cuando yo salía. Nada más" (Zapata, 1963: 36).

De forma permanente estas experiencias le irán brindando al lector una radiografía de la vida de los personajes que se irán desplazando como una espiral a lo largo de la historia. La presencia de esta memoria individual que toma múltiples matices permanecerá como insumo constante dentro de la obra para reunir las piezas de la identidad incógnita del niño. De acuerdo con lo anterior, un suceso, como fue la aparición de Jesús, Estanislao o Gil, permitió reconstruir las vidas expuestas por el autor dentro de la obra, con aquel carácter de universalidad que facilita al lector relacionarlo con su experiencia social: o, ¿quién no es capaz de reconocerse en una Ana Peñaranda, en una Susana, en una Otilia?.

Este efecto de "realidad" o cotidianidad inserta en la historia de Detrás del rostro se comprende a partir de una escritura cargada de diálogos intra-textuales que se articulan a partir de los relatos epistolares de Susana u Octavio y desde dimensiones filosóficas que abordan la carga y responsabilidad moral y social del doctor Jaurátegui o del Juez de menores cuando resultan reflexiones como la del galeno: “¿Sería posible que mi obsesión por el psicoanálisis aplicado a la conducta del delincuente pudiera amputar mi sensibilidad social, incluso para la suerte de los niños reclusos a los que trataba diariamente?" (Zapata, 1963: 21).

Frente a la defensa del rol que a cada individuo le compete dentro de un sistema, estos dos personajes elevan dimes y diretes en el que se establece una crítica a un sistema de vigilancia y corrección que por un lado no puede ignorar la ley, pero que por otro aplasta al individuo y toda esperanza de reforma social a través de su aplicación. En una frase expuesta en la novela se deja entrever esta intensa crítica a una realidad de las relaciones de poder que cuestiona el personaje del doctor Jaurátegui: "El juez y el guardián se fundían en una sola imago: la antijusticia” (Zapata, 1963: 124).

A través de una situación particular entre estos dos personajes (Jaurátegui y el Juez de menores) Manuel Zapata Olivella nos desarma frente a los infortunios de la justicia presentados en la obra, 
no tan alejado de la realidad latinoamericana. Así, esta es una escritura que se arriesga a re-mover y cuestionar los cimientos de la institucionalidad, pero que también propone los principios de la dignidad humana como parte su propia del ser. A propósito de la conversación entre Jaurátegui y el Juez de menores, este último le responde: "No es la primera vez que se me acusa de ser desalmado, rigurosos, ciego, arbitrario. Mi Freud son los códigos. Aquí está previsto todo, no hay sino leer y aplicar. Pero a diferencia de Freud, los códigos no se inmiscuyen en la generalidad de la vida" (Zapata, 1963:133). Y se agrega más adelante: "si hay sadismo, no es de quien aplica la ley, sino del Legislador" (Zapata, 1963: 135).

Es precisamente la palabra la que permite reconocer en las intersubjetividades diferentes formas de asumir el tiempo y el espacio, así como los lugares de enunciación desde donde se perciben las experiencias de cada uno de los personajes. Quedan desdibujadas temporalidades ocultas que se desplazan a lo largo de la historia, en especial las que conciernen a Otilia y su natural apatía por la madre: las que quedan expuestas no están exentas de dramatismo, dolor y ansiedades. Sobre el personaje de Otilia, su madre expresa: "A la muñeca le pintó bigotes y la vestía con pantaloncitos. Comenzó a tener demasiado interés por los varones. Desde muy pequeña esta fue una gran preocupación para mí." (Zapata, 1963: 55).

El acento permanente de reclamo y culpa se repite en los personajes de Ana Peñaranda, Susana y Otilia, tres mujeres que luchan con sus orígenes y con la carga del género. En el caso de Otilia se desplaza a un mundo cuyo tiempo es líquido pues se representa a partir del carácter inestable de la adolescencia. Su personaje es representado y construido bajo el imaginario de la carga generacional de la adolescencia femenina, pensada como irracional e inestable: "Los uniformes blancos le aterrorizaban desde que fue forzada a revelar su sexo herido al médico en Ibagué" (Zapata, 1963: 56). En su caso, el objeto, el caballo, desempeña un lugar dramático dentro del texto pues lleva al lector a descifrar las dimensiones de significado que ella le adjudica (Baudrillard, 1995:16). En la historia, Otilia personifica una especie de crisis de identidad asociada con el desarrollo de su sexualidad por lo que en algunas escenas con el psicoanalista se la relaciona con una especie de fetiche por un objeto del consultorio del médico.

Es el doctor Jaurátegui quien, junto a Estanislao, Jesús o Gil, conceden potencia a la historia. De la forma en que son representadas sus historias parecieran complementarse, pues Estanislao estimula en el médico una agencia detectivesca que termina cuestionando su propio trabajo y enfrentándolo a la hostilidad de un sistema de justicia completamente marginal a su función social. Es un personaje que tiene la capacidad de desplazar el tiempo dentro de la obra, de romper la linealidad de la historia al suscitar la escritura del relato de la vida del joven a Octavio Guzmán y en sus constantes búsquedas a partir de los cuestionamientos a distintos personajes.

En Detrás del rostro, el plano narrativo de la ciudad se expone como un escenario de fugas, búsquedas y des-encuentros. Aquí se representa aquel espacio de modernidad que se contrapone a su 
visión positiva que encarna el progreso. Manuel Zapata Olivella narra este lugar como espacio de hostilidades y contradicciones sociales, como en la escena de la protesta de los gamines que presencian Susana y Otilia: “ ¡No queremos quedarnos toda la vida en la calle esperando el momento en que tengamos que robar para poder comer! i Vivimos de lo que la gente nos regala, pero cada día nos dan menos!" (Zapata, 1963:149).

También es importante registrar que en esta re-lectura de Detrás del rostro es posible re-conocer el interés del autor por destacar la agencia de los estamentos de vigilancia y control: familia, escuela, cárcel y hospital y la forma en que cada uno opera dentro del conjunto de relaciones imbricadas en las historias. Se refleja en ellos el funcionamiento de un sistema social y político precario y cuyos fundamentos morales se demarcan por la tradición. En ello quedan expuestos vicios del sistema, pero también un intento por organizar un control social fundado en la burocracia.

Finalmente se hace necesario reconocer el aporte significativo de Detrás del rostro ya que presenta una forma de narrar la violencia a partir de la historia de un niño de confuso origen y destino. Los efectos de esta experiencia que se proponen en la historia señalan en este hecho una marca generacional y de clase social: al niño campesino víctima del contexto social y político. Desde los planteamientos del relato literario que nos ofrece la obra, la literatura se posibilita como un espacio de denuncia que socava el orden de las cosas y la propia estructura social e institucional. Deja entrever en el contexto en que fue escrita que la violencia pudo posicionarse como tema de reflexión, encarnar una voz vulnerablemente social y que a partir de ello actualiza a la luz de nuestro presente nuestras lecturas del contexto. Se constituye en un ejercicio de memoria que determina en su genealogía literaria un insumo potente para abordar la Historia. ${ }^{12}$

\section{Consideraciones generales}

La narrativa hispanoamericana, en general, entrañó un esfuerzo y proceso de adaptación del hombre (del universal) a las condiciones de una doble realidad, telúrica e históricamente dada, propia del continente, con sus variantes regionales. En lo geográfico, conflicto y la adaptación del hombre con respecto a la Naturaleza, cuyas poderosas fuerzas territoriales (pampas, selvas y montañas) van modelando en gran parte sus caracteres y sus hábitos. En lo histórico, conflicto y adaptación de la cultura occidental moderna a las viejas estructuras psíquicas y sociales de la tradición colonial. A la vez, en relación con los factores territoriales, han moldeado hereditariamente, en parte, costumbres y caracteres. Del juego de esos tres elementos (geografía, historia y territorio) se compone toda la novelística americana del XIX, y casi toda la del XX, y advertimos el casi porque, mayormente en el segundo tercio de este siglo, han aparecido algunas expresiones de otra índole: la experiencia del hombre en el clima universal de civilización de las grandes ciudades, novela de tipo íntimamente más semejante a la europea, aunque sus circunstancias ambientales se diferencien (Zum, 1959:11-12)

\footnotetext{
${ }^{12}$ Escribo Historia con "H" como una forma de exponer su régimen de historicidad moderno, que a mi parecer aún prevalece a pesar de que se intente desplazar hacia campos interdisciplinarios.
} 
Como producto de la realidad expuesta, en buena parte de los países latinoamericanos, a comienzos del siglo XX, varios escritores y artistas jóvenes, aprovechando el auge e innovación de los medios de comunicación, se unieron en torno al propósito de construir un ideario que les permitiera expresar de manera auténtica sus realidades sociales (Casas, 2006: 67). La literatura, como parte de esta tendencia, no se quedó atrás. Múltiples publicaciones asociadas a la realidad socio-histórica proliferaron en Latinoamérica, incluido Colombia. La novela del escritor Manuel Zapata Olivella, Detrás del rostro (1963) es evidencia de ello. Y se hace importante resaltar su presencia en la genealogía literaria puesto que es precisamente el género novelístico el que se interesa en gran medida por reflexionar sobre temáticas como la violencia, cuando aún desde las ciencias sociales y humanas se tornaba tímida. Esto es, el valor de la literatura como una fuente primaria para el estudio del período de la violencia queda expuesto al comprender la escritura literaria como acto de lectura de los personajes que la constituyen. Esto es, el llamado hacia la intensa relación que propone el autor con su propia tradición a partir del ejercicio de su imaginación literaria (Ortega, 2016: 69)

Por otro lado, el conjunto de experiencias que se presentan en la historia de Detrás del rostro nos invitan a re-pensar nuevas formas de percepción del contenido literario a partir de sus referencias históricas. En el término de pacto de lectura estas resonancias del contexto en el ejercicio lector van removiendo a nuestro presente las huellas de un pasado literario en sí mismo reflexivo, auténtico, social y crítico que parten de un ejercicio de memoria en la que se recorre no sólo un contexto, sino la humanidad de los personajes y se expresa una sobrecarga de sentidos marcados en la propia realidad del periodo histórico que aborda.

En términos historiográficos la violencia como tema no se encuentra exenta de "ficción" en tanto los historiadores re-interpretamos la historia a partir de los documentos y de ejercicios de investigación. La mirada que se obtiene se remite a prácticas discriminatorias desde la heurística de las fuentes y al sometimiento de una "supuesta" distancia cronológica del investigador con su objeto de estudio. Bajo la premisa rankiana, aún vigente, de "contar las cosas como realmente pasaron" se exime de cierta sensibilidad al aplicar las técnicas de la escritura, un uso de determinadas categorías y las eternas tensiones con la práctica interdisciplinar. ${ }^{13}$

En este sentido, la pretensión de este ensayo es en sí exponer un tipo de relación dialógica entre la historia y la literatura. ¿Puede o no ser la literatura una fuente histórica? ¿Quién lo decide y en qué momento? No desconocemos ni hemos dejado de experimentar tensiones en este proceso. En el ámbito de las Ciencias Humanas aún pervive el fantasma del purismo que se hace necesario incomodar. Como lo han hecho intelectuales como Manuel Zapata Olivella, este trasegar ya concede unos frutos. Por un lado, la condición de posibilidad que presenta este mismo escenario de acercamiento a la literatura a una historiadora. Por el otro, el surgimiento y la consolidación de los

${ }_{13}^{13}$ Tengo que aclarar que me refiero al historiador alemán Leopold von Ranke quien en su libro Historia de los pueblos latinos y germánicos 14941514 acuña este método rector de la práctica histórica y que aún pervive en nuestra disciplina. 
estudios culturales y los estudios críticos, escenario donde ha sido posible palpar encuentros entre la historia, la literatura, la filosofía y el género, entre otras.

¿Cómo llamaríamos a esta apuesta metodológica? Por el momento lo asumimos como una mirada de la literatura desde la historia cultural. Esto es, sometiendo a consideración el sentido de los discursos vinculados a la novela Detrás del rostro, las prácticas que se evidencian en el ejercicio de escritura del autor y las representaciones que dialogaron con la realidad social de mediados del siglo XX en Colombia.

La intensa producción que afortunadamente ya se encuentra presente en la disciplina histórica y sociológica da cuenta del creciente interés por comprender nuestra realidad social. ${ }^{14} \mathrm{Si}$ por un lado, la historia permite un acercamiento denominado "objetivo" a los hechos, la creación literaria actualiza ese debate en torno a temas como la violencia, comprendida desde las dimensiones de los límites y posibilidades de escritura que presenta el autor con su producción. Puntos de encuentro.

En el marco de la celebración del Centenario de Manuel Zapata Olivella, podemos decir que su producción literaria queda expuesta como la evidencia de un proyecto cuya agencia creativa sigue manteniendo vínculos muy fuertes con la historia: nos invita a re-pensar y re-escribir el lugar y valor de una genealogía y una memoria literaria. Este aspecto denota que la presencia del intelectual negro permanece vigente y da fe de su presencia en el campo artístico e intelectual de nuestro país donde se posiciona como interlocutor de su realidad social y política (Bourdieu, 1980: 97). Esta capacidad de Zapata Olivella para comprenderse en un contexto político hostil deja entrever también la capacidad del autor para enfrentarse como expresa Marc Angenot a las "hegemonías de lo pensable y lo decible," (2010: 228) ${ }^{15}$, esto sin desconocer el precio de la rebeldía en nuestro país. ${ }^{16}$

Como expresa Ángel Rama, las motivaciones de cualquier obra literaria son casi siempre múltiples, como son múltiples los mensajes que transporta. Incluso entre ellas puede faltar -como percibió lúcidamente Hermann Broch- el propósito expreso de producir una obra de arte; pero la importancia y pervivencia de esta, responderá al significado artístico con que haya sido construido (Broch, 2009: 3). Es este "añadido" estético a las motivaciones básicas del autor, hayan sido religiosas, morales, políticas o simplemente confesionales, el que articula los mensajes y les confiere

\footnotetext{
${ }^{14}$ Desde un enfoque de las ciencias sociales, el tema de la violencia es inaugurado por la obra de Orlando Fals Borda, Eduardo Umaña y Germán Guzmán (1968), La violencia en Colombia, obra que irrumpió en la escena para evidenciar los elementos estructurales de este fenómeno. Más tarde Álvaro Tirado Mejía con el texto La violencia en Colombia (1995) acompañaría estas reflexiones desde una perspectiva histórica de la violencia, apoyado en las reflexiones de colombianistas como Malcom Deas y David Bushnell, desde una perspectiva de la historia política con una estructura más lineal, cronológica y narrativa del fenómeno.

${ }^{15}$ En su momento, Manuel Zapata Olivella fue encarcelado por el SIC durante el gobierno de Laureano Gómez, después de que fuera invitado a la Conferencia de Paz de los pueblos de Asia y África. Esto por considerar que sus ideas eran contrarias a la política internacional del régimen.

${ }^{16}$ Testimonios de ello son los magnicidios que tristemente registra la historia de Colombia a lo largo del siglo XX y la presencia de un conflicto armado, vigente hasta nuestros días.
} 
sentido a veces discordando con el propio autor. Entonces rozamos las fuentes profundas del perspectivismo ideológico, las que impregnan y cohesionan la obra más allá de los discursos doctrinarios explícitos que contenga o de las intenciones voluntarias del autor (Rama, 2008: 262). De esta forma, la potencia inventiva de Manuel Zapata Olivella está sujeta a múltiples interpretaciones, pero puede confluir en destacar el trabajo con una re-escritura de experiencias, la fabulación de una cruda realidad social que no se aleja de dimensiones "realísticas" y un ejercicio de creación estética de fuerte vínculo con su presente inmediato de producción, movilizando referentes críticos del contexto histórico de la Primera Violencia.

Finalmente, hay que resaltar que el escritor Manuel Zapata Olivella permanece vigente en la genealogía literaria del país y nuestra deuda radica en que esta re-visita se constituya en una propuesta verdaderamente crítica. Ante todo, fue un hombre comprometido con la cultura y dispuesto a pensar-se como agente social e investigador de la identidad colombiana. A partir de este eje su labor se constituyó en la comprensión de dicha cultura en términos locales y nacionales, la forma en que nuestra experiencia histórica podía encontrar sentido en las experiencias humanas y cómo estas podían exponerse a partir de ejercicio de creación o de viva voz. El tema central de su narrativa fue la historia y la cultura de su natal Caribe colombiano, en especial de los negros e indígenas (Colprensa, 2019: 1). Como diría Paul Ricoeur, su experiencia estuvo mediada por esa "pequeña felicidad de la percepción" encarnada en su color de piel y en la clara diversidad expuesta en las tradiciones y costumbres de nuestro país. Fue un hombre polifacético, viajero, apasionado por el conocimiento, la libertad de pensamiento y las artes. Representa al agente cultural propio de la Colombia de mediados del siglo XX, donde hombres y mujeres artistas tuvieron múltiples inquietudes alrededor de la pintura, la danza, el cine, la fotografía, entre otros. Junto a coterráneos y contemporáneos forjaron uno de los períodos históricos más prolíficos en el campo cultural en Colombia, aún a la espera de ser abordado desde las distintas disciplinas, entre ellas la literatura que consideramos como un insumo significativo para la Historia.

\section{BIBLIOGRAFÍA}

Angenot, M. (2010). El discurso social: los limites históricos de lo pensable y lo decible. Buenos Aires: Siglo XXI.

Arboleda, S. (2011). Le han florecido nuevas estrellas al cielo: suficiencias intimas y clandestinización del pensamiento afrocolombiano. (Tesis de doctorado). Universidad Andina Simón Bolívar, Quito.

Bandrillard, J. (2000). Contraseñas. Barcelona: Anagrama.

Banrepcultural. (2020). La prensa en Colombia. Banrepcultural. Recuperado de https://enciclopedia. banrepcultural.org/index.php?title=La_Prensa_en_Colombia 
Bello, C. (2008). La violencia en Colombia: Análisis histórico del homicidio en la segunda mitad del Siglo XX. Revista Criminal, 50(1), 1-12.

Bermúdez, S. (1994). Hijas, esposas y amantes. Género, clase etnia y edad en la historia de América Latina. Bogotá: Uniandes.

Bloch, M. (2001). Apología para la historia o el oficio del historiador. Ciudad de México: Fondo de Cultura Económica.

Bourdieu, P. (1980). Campo de poder y campo intelectual. México: Siglo XXI.

Bourdieu, P. (2011). La ilusión biográfica. Acta Sociológica, (56), 121-128.

Braun, H. (1987). Mataron a Gaitán. Bogotá: Universidad Nacional de Colombia.

Broch, H. (2009). Voces. México: Universidad Nacional Autónoma de México.

Bushnell, D. (1994). Colombia. Una nación a pesar de sí misma. De los tiempos precolombinos a nuestros días. Bogotá: Planeta.

Casas, J.(2006). Nacionalismo y bachuismo en las esculturas boyacenses. Educación y ciencia, (9), 63-72.

Castro-Gómez, S. (2009). Tejidos oníricos (Movilidad, capitalismo y biopolítica en Bogotá (19101930). Bogotá: Pontificia Universidad Javeriana.

Colprensa. (2019). Manuel Zapata Olivella. Radio Nacional de Colombia. Recuperado de https:// www.radionacional.co/noticias/actualidad/manuel-zapata-olivella-literatura-colombiana-mincultura.

De Certeau, M. (1996). La invención de lo cotidiano. Artes de hacer. México: Universidad Iberoamericana.

Díaz-Granados, J. (2003). Manuel Zapata Olivella. Su vida y su obra. Recuperado de https:// manuelzapataolivella.co/pdf/MZO-SuVidayObra.pdf

Editorial. (23 de julio de 1950). El seguro de enfermedad-maternidad. El colombiano. 
Fals, O. (1962). La violencia en Colombia (Vol. I). Bogotá: Taurus.

García, G. La Hojarasca. (1955). Colombia: Random House.

Ginzburg, C. (1982). El queso y los gusanos. El cosmos según un molinero del siglo XVI. España: Muchnik.

Hall, S.(1997). Representation: Cultural Representations and Signifying Practices. Londres: Sage Publications.

Medina, A. (2019). La renovación vanguardista, 1910-1950. Banrepcultural. Recuperado de http:// www.banrepcultural.org/coleccion-de-arte-banco-de-la-republica/la-renovaci\%c3\%b3n-vanguardista-1910-1950

Múnera, A. (2005). Fronteras imaginadas. La construcción de las razas y de la geografía en el Siglo XIX colombiano. Bogotá: Planeta.

Naranjo, J. (2016). La Marquesa de Yolombó. Credencial Historia, (110),1.

Ordóñez, M. (1999). La vorágine. Revista Credencial, (10),1.

Ortega, A. (2016). Filiaciones, huellas literarias, reescrituras: cuatro novelas ecuatorianas. Saga. Revista de Letras, (6), 68-100.

Perrot, M. (2002). Las mujeres y los silencios de la historia. En: Francoise Barret-Ducrocq. ¿Por qué recordar? (pp.55-61), Buenos Aires: Granica.

Prado, G. (2019). Hacer lo ajeno propio y lo propio ajeno. (Conferencia IV Encuentro Nacional de Literatura, Historia y Cultura). México: Universidad de Colima.

Rama, A. (2008). Transculturación narrativa en América Latina. Buenos Aires: El Andariego.

Restrepo, L. (1989). Literatura y pensamiento, 1946-1957. En: Álvaro Tirado. Nueva Historia de Colombia.Tomo VI.Literatura y pensamiento,artes, recreación (pp.65-108). Bogotá: Planeta.

Ricoeur, P. (2004). La memoria, la historia, el olvido. Buenos Aires: Fondo de Cultura Económica. 
Ruiz, R. (1965). Detrás del rostro, una novela ejemplar. Boletín cultural y bibliográfico, 8(1), 105-106.

Samper, D. (2014). Desde el fozo. El cuartelazo del general Melo. Credencial (15), 1.

Señal Memoria. (2012). Manuel Zapata Olivella. Un caminante de la literatura y la historia. Señal Memoria, Recuperado de: https://www.senalmemoria.co/articulos/manuel-zapata-olivella.

White, H. (1973). Metahistoria. La imaginación histórica en la Europa del siglo XIX. México:Fondo de Cultura Económica.

Zapata Olivella, M. (1949). Un colombiano en el cine azteca. Cromos.

Zapata Olivella, M. (1963). Detrás del rostro. España: Premio literario ESSO.

Zum, A. (1959). Índice crítico de la literatura hispanoamericana II. La narrativa. México: Guaraní. 